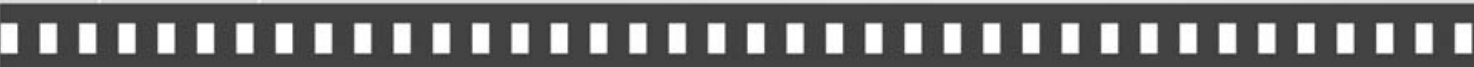

\section{Eternas macas, eternas marcas}

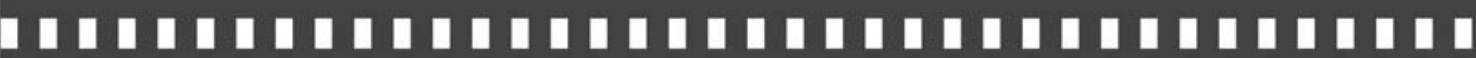

\author{
José de Arimathéia Cordeiro Custódio
}




\title{
Eternas macas, eternas marcas
}

Eternal stretchers, eternal wretches

\author{
Joséde Arimathéia Cordeiro Custódio*
}

\begin{abstract}
Resumo: Este artigo analisa fotografias de matérias publicadas em dois jornais diários da cidade de Londrina-PR. Demonstra a construção de determinados sentidos em torno do conceito de saúde pública, especificamente no que se refere ao fenômeno da superlotação hospitalar na referida cidade. Enfoca fotografias de matérias publicadas no ano de 2004, todas sobre o mesmo tema. Inicia com uma descrição do tema e da sua exposição pelos jornais, nem sempre correspondentes à realidade, mas que podem influenciar no imaginário do leitor. Num segundo momento, analisa algumas fotografias mais profundamente, e expõe a própria repetição de imagens como artifício argumentativo de convencimento e fixação de uma idéia determinada na mente do leitor.
\end{abstract}

Palavras-chave: fotografia jornalística; sistema de saúde; superlotação hospitalar; construção de sentido.

\begin{abstract}
This article analyses photographs of reports published by two daily newspapers of Londrina-Paraná. It shows the building of certain meanings around the concept of public health, especially on the phenomenon of hospital overcapacity in that town. The focus is on reports published in the year of 2004, all of them about the same theme. It begins with a description of subjective issues exposed in the newspapers, not corresponding to reality, but able to influence the imaginary of the readers. On a second moment, the essay analyses some photographs deeper and exposes the repetition of the images as an argumentative scheme for persuading and fixing a certain idea in the reader's mind.
\end{abstract}

Key-words: journalistic photography; health system; hospital overcrowd; public health; building meaning.

\footnotetext{
*Especialista em Fotografia e Doutor em Estudos da Linguagem pela Universidade Estadual de Londrina. Professor colaborador do Curso de Especialização em Fotografia da Universidade Estadual de Londrina.
} 


\section{Introdução}

Que imagens vêm à cabeça diante da expressão: "saúde pública do Brasil”? O retrato deste aspecto da realidade nacional mostra repetidamente a mesma face: gente demais, vagas de menos. Apesar de o atendimento público à saúde consistir numa rede complexa, num sistema, o foco sobre a questão é rotineiramente reduzido a uma pobre variedade de imagens, praticamente sempre orbitando em torno de uma ponta do problema: as instituições hospitalares - públicas, preferentemente.

Quando uma cidade como Londrina - centro de uma região metropolitana de cerca de um milhão de habitantes, mas com influência bem maior - possui um hospital-escola terciário, com três centenas de leitos, de atendimento exclusivo para o Sistema Único de Saúde, referência nacional em várias especialidades, com uma centena e meia de residentes de mais de 30 áreas, e que recebe pacientes de todas as regiões do Brasil e eventualmente até do exterior, é óbvio que as atenções se voltam majoritariamente para ele. Ainda que esta importante cidade possua também meia centena de unidades básicas de saúde e vários outros hospitais, inclusive particulares que recebem pacientes do SUS, o Hospital Universitário (HU) é sempre a manchete do “caos” da superlotação hospitalar.

Esta afirmação não é mera figura de linguagem. Outro estudo nosso - realizado em 2003 num conjunto de 29 matérias de dois jornais impressos da cidade sobre o tema "superlotação hospitalar", reunidas pelo HU a pedido do Ministério Público - revelou que apenas 7 títulos não se referiam expressamente aos hospitais. Por outro lado, em 15 deles apareceu o HU. Em outros 7, o título falou em "hospitais" ou "hospitais públicos". Ou seja, o foco das notícias recai insistentemente sobre estas instituições, como se elas fossem não reflexo, mas centro de um problema social. Percebe-se aí o fenômeno da "hospitalização" da saúde, abertamente construído pela imprensa, não apenas escrita. Esta é a representação simbólica gerada pela cobertura midiática. 
As imagens que ilustram e moldam a percepção dos leitores acompanham logicamente a construção de sentido dos textos. O título atrai, a retranca orienta, o texto conduz e a fotografia, graças à sua icônica capacidade de retratar a realidade, não deixa opção ao leitor a não ser acatar o exposto. Mas um olhar mais demorado e de perto pode suscitar reflexões e revelar ideologias.

\section{Realidade objetiva}

Tecnicamente falando, as unidades de Pronto Socorro do Hospital Universitário de Londrina - o maior hospital público do norte do Paraná - estão sempre superlotadas, isto é, estão sempre com sua capacidade máxima de lotação mais um número variável de pacientes internados. Há no setor 37 leitos para internação (11 pediátricos e 26 adultos, sendo 14 para pacientes do sexo masculino e 12 para o feminino) - esta é a capacidade de internação.

Fora estes, existem 34 macas, entre boxes de atendimento, corredor, Pronto Socorro de Espera e sala de emergência. As macas são para atendimento emergencial, não são leitos cadastrados pelo Sistema Único de Saúde. É comum, além dos leitos, haver uma ocupação de 24 a 32 macas todos os dias. Portanto, há superlotação diária. A imprensa, porém, só demonstra interesse quando o número de internados excede inclusive as 34 macas, ou seja, quando os pacientes passam de 71. Nos dias mais difíceis, o Hospital Universitário teve mais de 90 pacientes nos apertados corredores do Pronto Socorro - alguns internados em bancos e cadeiras.

O Pronto Socorro do Hospital Universitário nunca fecha; ele presta atendimento 24 horas por dia, sete dias por semana. A média é de um paciente entrando a cada oito minutos, ininterruptamente. É preciso esclarecer que há cinco Pronto-Socorros: Médico (PSM), Cirúrgico (PSC), Pediátrico (PSP), Obstétrico (PSO) e Ortopédico (PSOrt). Pode ocorrer, em função da alta demanda, de um ou mais suspender o 
atendimento, o que significa que, a partir de então, receberá apenas casos de urgência (um caso grave encaminhado de outra instituição) e emergência (trauma). Assim, por exemplo, quando não há vagas na UTI Neonatal, é suspenso o atendimento no PSO, que normalmente recebe pacientes de risco (gravidez precoce, parto prematuro, etc.). Ao mesmo tempo, todos os outros podem estar funcionando normalmente. Uma suspensão pode durar apenas algumas horas ou dias, dependendo de uma série de fatores.

Nada disso é explicado quando os principais jornais registram, periodicamente, a condição de superlotação hospitalar. Porém, como ela é rotineira, surge uma dúvida: por que às vezes ela é notícia, e às vezes não? Qual o critério? Qual o assunto que precede a este na pauta do dia, e que está ausente quando existe o interesse pelo “caos” na saúde pública? Tais indagações sugerem que a decisão por fazer ou não uma matéria sobre a situação dos hospitais recai sobre um agente invisível, aparentemente fora da situação enunciativa do texto impresso.

De qualquer maneira, quando a matéria é feita, logicamente ela fica valorizada com o recurso da imagem, tanto nos jornais quanto na televisão. É uma análise de tais imagens que faz este artigo. O corpus foi selecionado a partir do arquivo de clipping de jornais da Assessoria de Comunicação do Hospital Universitário de Londrina.

$\mathrm{O}$ ano de análise escolhido foi 2004. Foi um ano em que o HU apareceu muito nos jornais, em razão de uma série de notícias: movimento grevista com um dia de paralisação; fechamento de leitos de enfermarias por falta de pessoal; mobilização de residentes em favor da instituição. Foi também ano eleitoral, e o hospital é freqüentemente visitado por candidatos, assim como é sempre alvo dos discursos, como maior expressão da assistência à saúde pública da região.

Todos os recortes de 2004 arquivados na Assessoria foram consultados e, entre todos os assuntos, foi escolhido o da superlotação hospitalar - que não ocorreu somente em 2004, mas vem desde os anos 70 e prossegue até hoje. Apenas para criar um ponto comparativo, registramos uma matéria sobre o assunto, de 1993. Os jornais recortados 
são a Folha de Londrina e Jornal de Londrina. Foram selecionadas apenas as matérias que tratam deste assunto, diretamente ou com pelo menos uma menção ao fenômeno da superlotação. $\mathrm{O}$ ano de 2004 trouxe muitas matérias sobre falta de vagas em Unidades de Terapia Intensiva, mas tais matérias só entraram neste estudo quando o texto e/ou a fotografia citavam o Pronto Socorro.

A grande maioria das matérias usa fotografias. Umas poucas - menos de $10 \%$ - trazem apenas texto. Foram desprezadas. Algumas matérias trazem mais de uma foto. Neste caso, apenas a principal (maior) foi levada em conta. Fotos secundárias, como a de um entrevistado, não entraram na análise.

Num primeiro momento, este estudo observa a repetição de imagens selecionadas para ilustrar a matéria. Comenta também o uso de fotos que mostram o rosto dos pacientes. Num segundo momento, a análise se aprofunda em um conjunto menor de fotografias: aquelas que ilustraram matérias publicadas no mesmo dia pelos dois jornais. Curiosamente, na maioria das vezes não houve tal coincidência, mas apenas cinco vezes no ano: nos dias 19 e 29 de janeiro, 13 de maio, 24 de setembro e 5 de novembro.

\section{As eternas macas}

Já virou clichê: nada retrata melhor as dificuldades do atendimento público à saúde do que pacientes em macas em um longo corredor. A imagem, que virou ícone e já se banalizou, de tão gasta, tem sido usada na imprensa escrita de Londrina há muitos anos. Uma matéria da Folha de Londrina de 11 de agosto de 1993 (figura 1), intitulada "Lotado, HU só atende as emergências" - traz uma fotografia colorida que mostra pacientes sentados e deitados em marcas encostadas nas paredes de uma sala. Alguns acompanhantes aparecem também. Uma paciente aparece em primeiro plano, à esquerda, sentada na maca. Tem um curativo no olho direito. 


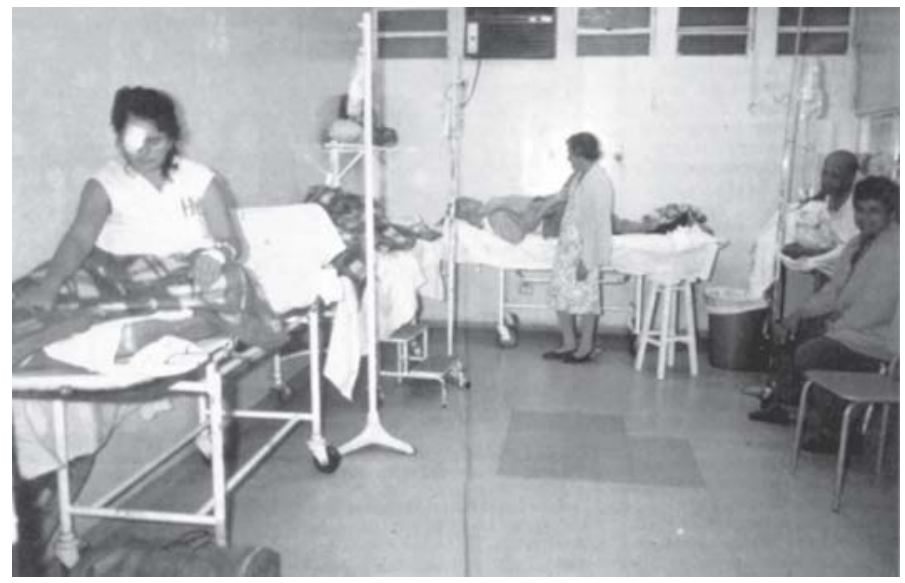

Figura 1 - Folha de Londrina 11/08/1993

Foto: Milton Dória

Fotografias de pacientes em corredor ou em enfermarias foram as mais utilizadas pelos jornais em 2004. Na Folha de Londrina, de 26 matérias com foto, 18 (cerca de 70\%) retratam o corredor principal ou uma das enfermarias do Pronto Socorro. As demais variam entre fotos da sala de espera cheia de gente, retratos de pacientes ou outras. Seis fotos permitem identificar claramente os pacientes, à medida que seus rostos foram completamente expostos. Em casos em que o paciente é o personagem - porque denunciou a demora, por exemplo - é lógico que ele seja retratado. Mas tais ocorrências são exceções. A maioria dos pacientes expostos estavam nas macas. É importante ressaltar que, embora o hospital seja público, os pacientes não são.

O Jornal de Londrina fez menos matérias com fotografias sobre o assunto no ano - 18, de acordo com o arquivo da Assessoria de Comunicação do Hospital Universitário. Destas, dois terços (12) foram tomadas no corredor ou numa enfermaria. Também em seis matérias pacientes podem ser identificados.

A exposição da figura humana, sem dúvida, é mais informativa e mais emocionalmente apelativa para o leitor, que pode se identificar com a situação, ao ver outro ser humano retratado pela matéria. Principalmente se o paciente retratado é um idoso, criança ou gestante. 
Parece impensável registrar uma superlotação hospitalar sem expor seres humanos. Mas é sempre uma questão de sentido construído, de recorte intencional e volitivo da realidade. Pois a imagem, apesar de tudo, é desumanizadora, porque generaliza o fato e ignora a história pessoal de cada paciente, assim como despreza outros fatores, como o tempo de permanência de cada um. O jornal circula no dia seguinte à tomada fotográfica e pode fazer crer que uma situação que já pode não existir mais - é comum a demanda diminuir em poucas horas pareça presente.

As imagens selecionadas para uma análise mais detalhada fornecem mais informações. São 13 fotografias em 12 matérias, das quais 5 mostram um corredor do Pronto Socorro; 6 retratam pacientes em uma enfermaria; e duas os mostram na sala de espera, aguardando pelo chamado.

\section{As eternas marcas}

“Drama no HU: 60 doentes para 26 vagas” é o título da matéria da Folha de Londrina de 19 de janeiro de 2004 (figura 2). A fotografia, em P\&B, ocupa quase um quarto do espaço da matéria. Mostra, em primeiro plano, à esquerda, um paciente de olhos fechados, deitado em uma maca, num corredor. Está sob uma coberta e sobre ela pode se ler "niversitário", identificando o local. Ao fundo, desfocados, aparecem mais três pessoas - uma outra paciente numa maca e duas que parecem ser acompanhantes - uma em pé e outra sentada num banquinho, ao lado de um leito, ainda mais ao fundo.

No mesmo dia, o Jornal de Londrina trouxe em sua manchete outro enfoque: "Lotado, pronto-socorro do HU volta a restringir atendimento”. Quase a metade do espaço da matéria é ocupado por duas fotografias, ambas em P\&B (figuras 3 e 4). A maior mostra o Pronto Socorro de Espera do hospital, com pacientes deitados, um acompanhante e uma provável auxiliar de enfermagem, atendendo um paciente sentado no leito. Não há leitos extras na sala, que tem a circulação livre na imagem. 


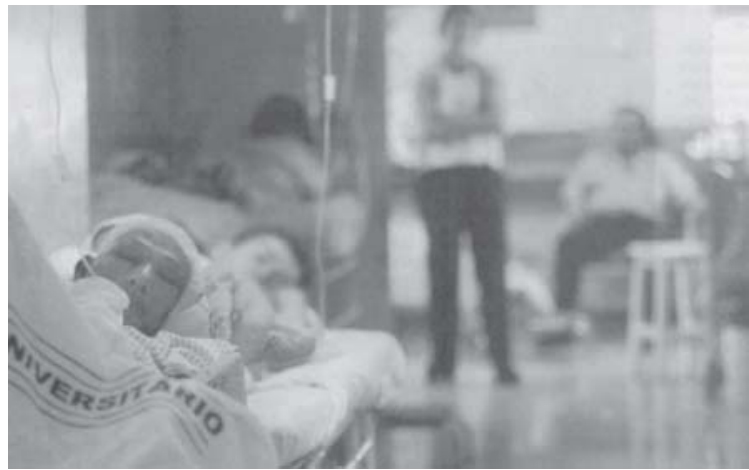

Figura 2 - Folha de Londrina - 19/01/2004 Foto: Devanir Parra

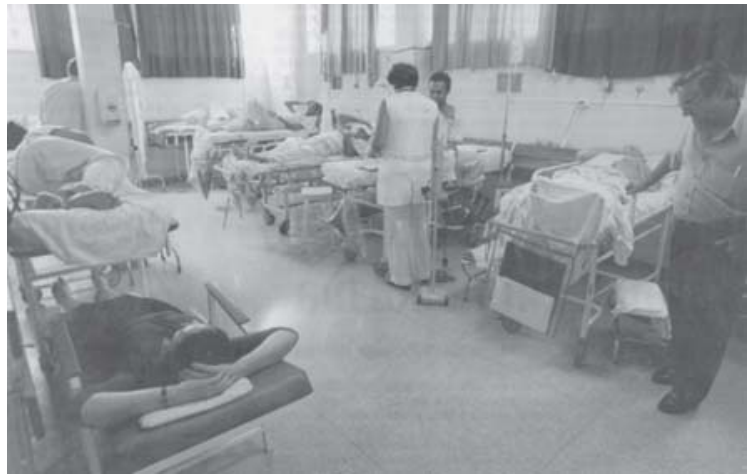

Figura 3 - Jornal de Londrina - 19/01/2004 Foto: Roberto Custódio

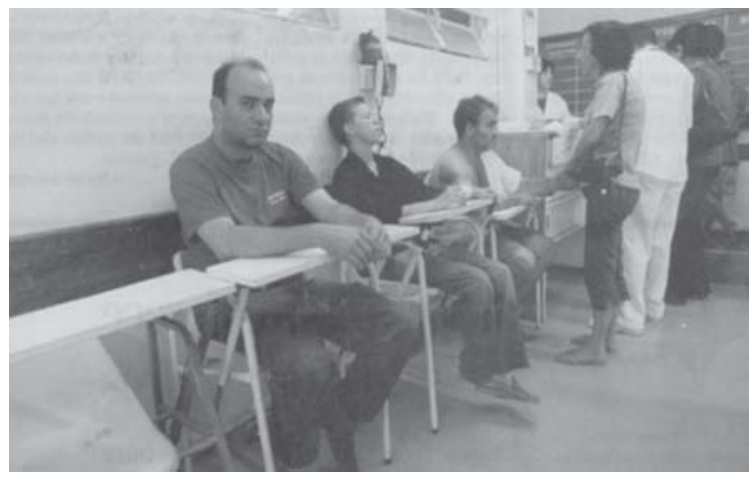

Figura 4 - Jornal de Londrina - 19/01/2004 Foto: Roberto Custódio 
A segunda fotografia mostra três pacientes sentados em cadeiras. A legenda a valoriza, ao dizer que a superlotação faz o atendimento ser feito "até" em cadeira. Mas há quatro cadeiras na fotografia, e a primeira à esquerda, em primeiro plano, está vazia. Ela só não atrai o olhar em primeiro lugar porque na segunda há um homem olhando para a câmera. O elemento humano é o que mais atrai o olhar do leitor da fotografia. Se o fotografado olha para a câmera, então, a atração é ainda maior. A idéia de lotação, porém, é reforçada no ponto de escape da foto, acima à direita (num trajeto conduzido pelas linhas das cadeiras), com quatro pessoas em pé, retratadas no canto. Fica a impressão de pouco espaço, de opressão.

No dia 29 do mesmo mês, a Folha de Londrina (figura 5) noticiou que "Superlotação suspende atendimento no HU”. Excepcionalmente, a fotografia que ilustra a matéria - e toma quase a metade do espaço, em P\&B - é da sala de espera, em frente aos guichês de triagem. Mostra várias pessoas sentadas, à espera da chamada. Um homem, ao fundo, está em pé, num guichê. À sua direita, três mulheres - percebe-se que a do meio é gestante - parecem formar uma fila. Mas também se vê dois guichês à esquerda, vazios. Um nem mostra um atendente. Também não se vê placas informando a suspensão de algum serviço, procedimento tomado nestes casos. Pode ser, porém, que o funcionário da triagem informasse oralmente. Vale observar que o olhar logo se fixa numa mulher, bem ao centro da foto. Mas ela não está tão próxima à câmera. Há um espaço vazio no banco ao seu lado.

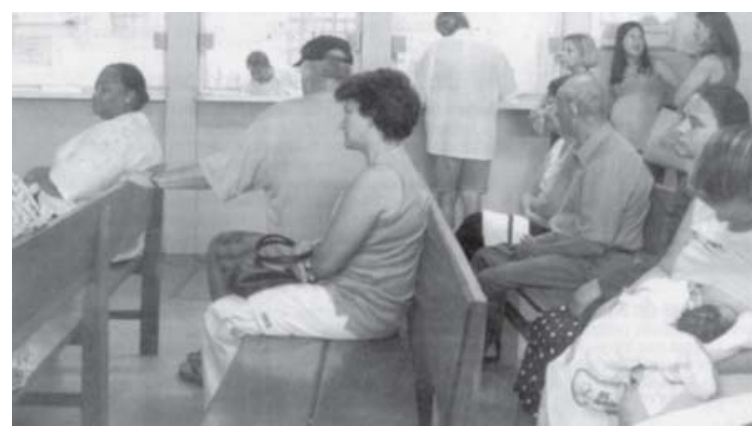

Figura 5 - Folha de Londrina - 29/01/2004

Foto: César Augusto 
A matéria do Jornal de Londrina, naquele dia (figura 6), traz o seguinte título: “HU enfrenta nova superlotação e fecha PS”. Já foram feitas as considerações acerca da "novidade” da superlotação e do “fechamento” do Pronto Socorro. Quanto à fotografia, pode-se dizer que, se ela tivesse sido feita ao mesmo tempo que a da Folha, teria mostrado seu fotógrafo. Ela foi tirada quase que diametralmente oposta à do outro jornal, como se o homem do guichê da outra fotografia estivesse às costas do fotógrafo. Assim, em ângulo oposto, no mesmo dia, o fotógrafo do JL fez seu registro no mesmo local - fora da unidade superlotada. Ambas as fotografias são mais frias, pois mais se referem à atitude de espera do que falta de espaço. São imagens de um dia comum na sala de espera.

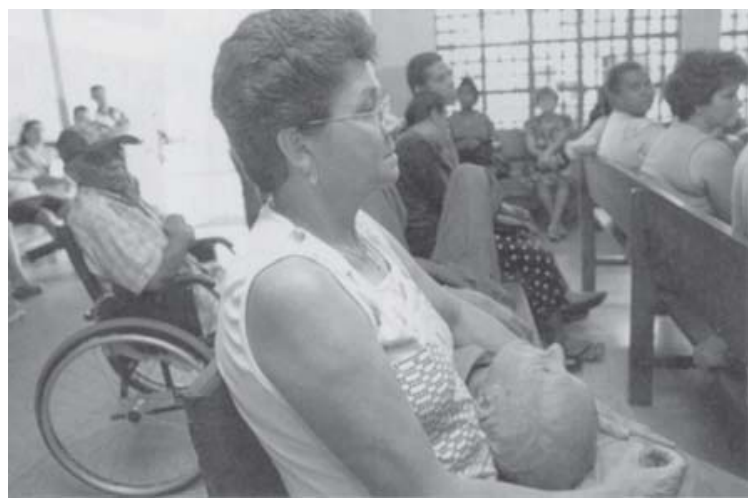

Figura 6 - Jornal de Londrina - 29/01/2004

Foto: Roberto Custódio

Três meses e meio depois, no dia 13 de maio, os dois jornais voltaram a destacar o fenômeno da superlotação, ao mesmo tempo. A Folha de Londrina traz um texto instrucional, como aquele que poderia estar na triagem do hospital: "Pronto-socorro: não há vagas”. Metade do espaço é dedicado às duas fotografias, em $\mathrm{P} \& \mathrm{~B}$ (figuras 7 e 8). A maior traz, à esquerda, em primeiro plano, a placa "sala de gesso", mas do Hospital da Zona Norte. A linha da porta e a maçaneta dividem a fotografia perfeitamente ao meio. Na metade direita, vê-se, desfocado pela distância, um paciente sobre uma maca, num corredor, coberto. Vê-se também o 
soro ministrado a ele num suporte. A fotografia menor retrata uma enfermaria na Santa Casa de Londrina, em que se pode contar cinco pessoas. O olhar se fixa primeiro num idoso, de costas, no ponto ouro. Uma paciente olha na direção da câmera. Mais discreto, no inferior da fotografia, um paciente esconde o rosto sob um boné.

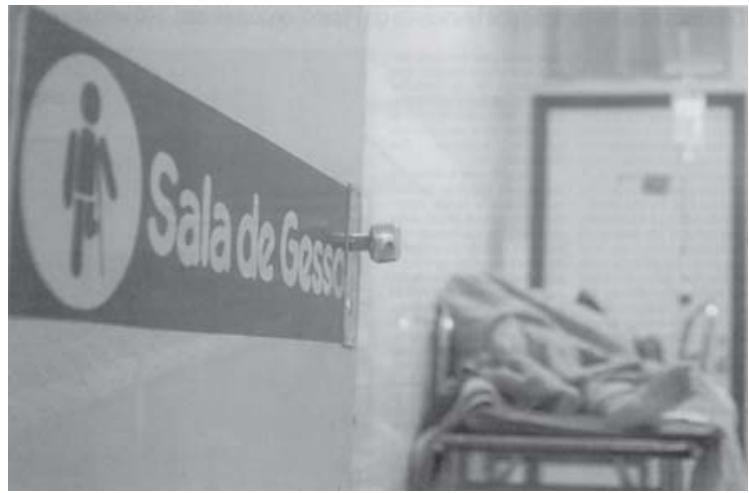

Figura 7 - Folha de Londrina - 13/05/2004

Foto: César Augusto

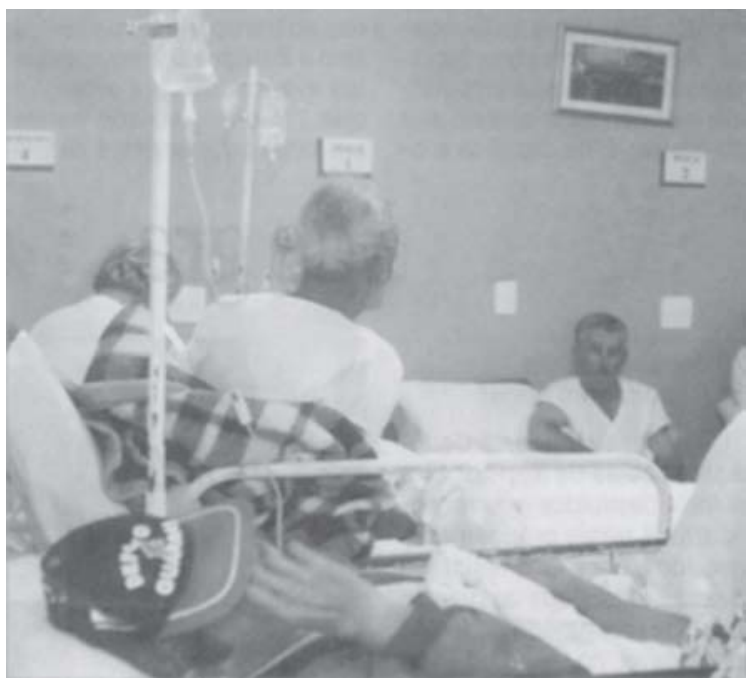

Figura 8 - Folha de Londrina - 13/05/2004

Foto: César Augusto 
O Jornal de Londrina traz uma explicação para a superlotação nesse dia: "Frio e greve da UEL superlotam hospitais", num dos raros casos de títulos diferentes. A grande e única fotografia em P\&B (figura 9) também mostra uma enfermaria da Santa Casa - pela aparência dos pacientes, é a mesma retratada no outro jornal.

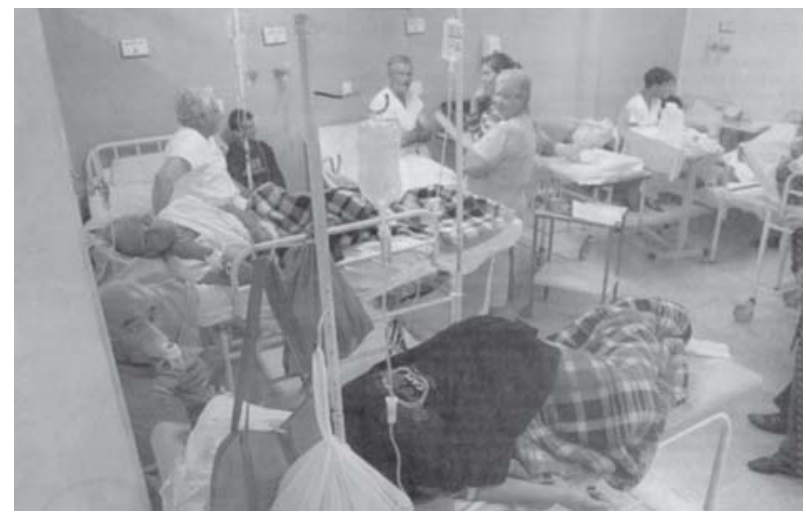

Figura 9 - Jornal de Londrina - 13/05/2004

Foto: Sem crédito

Muitas linhas se cruzam na imagem, reforçando a idéia de espaço ocupado. São as linhas dos suportes de soro, grades das macas, cobertas de cor xadrez, pés de cadeiras, das macas e de mesinhas, além da linha de uma parede, à esquerda. Parece que os pacientes estão em meio a uma teia. Alguns olham para a câmera - um deles, à esquerda, discreto, está inalando oxigênio , o que estabelece uma correspondência à idéia de "frio" do título (que traz problemas respiratórios). Já a expressão "greve da UEL” explica porque desta vez o HU não foi o alvo da fotografia, embora - como já se tenha sido enfático - o Pronto Socorro nunca fecha.

Passados outros quatro meses, a "Cidade enfrenta falta de UTI", segundo o Jornal de Londrina. A abertura da matéria lembra que "a situação no PS adulto também ficou complicada...”. O “PS adulto” (?), naturalmente, é o do HU.

A matéria do $J L$ traz duas fotografias coloridas (figuras10 e 11), que ocupam cerca de dois quintos do espaço total. A maior mostra um 
paciente sendo atendido numa das enfermarias do Pronto Socorro. O paciente quase não aparece. Uma funcionária, vestindo azul, ocupa boa parte da imagem. Do outro lado do leito, outra funcionária realiza um procedimento. À esquerda, dois funcionários deslocam uma maca - a imagem sugere movimento, mas como também ocupa a porção esquerda da fotografia, reforça a idéia de restrição de espaço. Uma máquina à direita ajuda a preencher o primeiro plano. A máquina faz ligação com o título, pois o paciente tinha indicação para UTI.

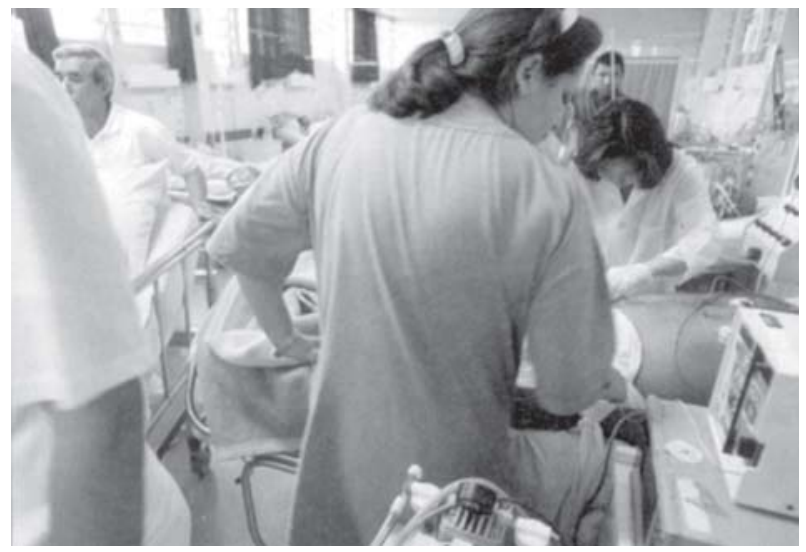

Figura 10 - Jornal de Londrina - 24/09/2004 Foto: Gilberto Abelha

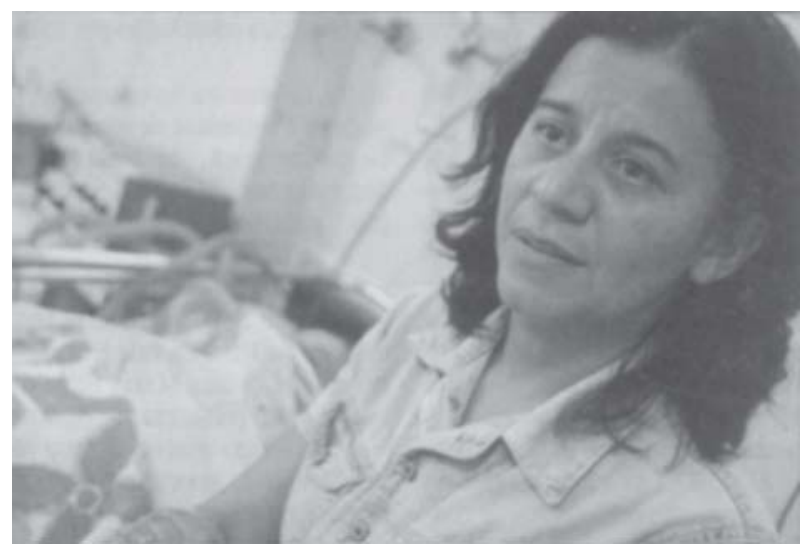

Figura 11 - Jornal de Londrina - 24/09/2004

Foto: Gilberto Abelha 
A fotografia menor traz em primeiro plano, à direita, uma entrevistada, acompanhante da mãe, internada. O leito com a mãe aparece desfocado, em segundo plano, à direita. Pode-se ver a paciente entubada.

A Folha de Londrina, na matéria “Cinco pacientes aguardam vagas em UTI”, inverte: traz uma grande fotografia (figura 12) - que ocupa mais da metade do espaço - com a mesma mulher que acompanhava a mãe. Embora em outro ângulo, a fotografia é muito semelhante: mostra, em plano mais aberto, a mãe entubada à esquerda e a filha à direita, com os braços cruzados, que faz eco à palavra “aguardam” do título. Ela não olha para a câmera, em nenhuma das fotografias.

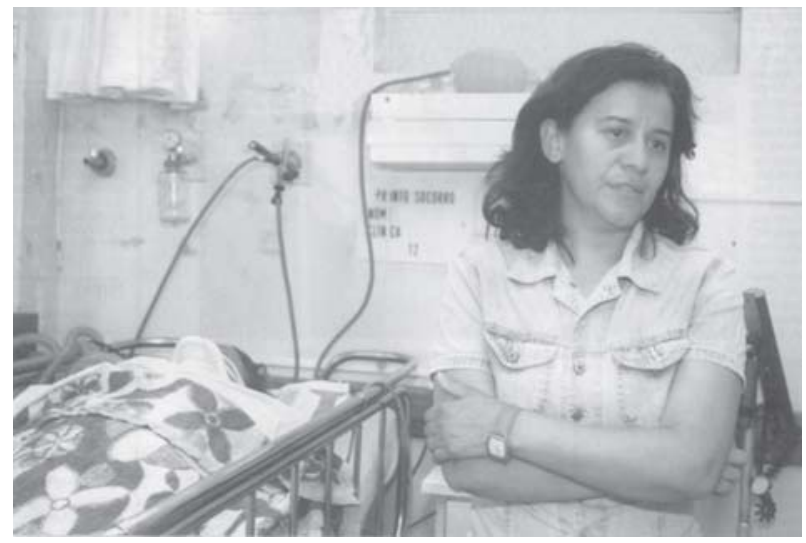

Figura 12 - Folha de Londrina - 24/09/2004 Foto: Karina Yamada

Apenas seis semanas depois os dois jornais voltam a publicar, no mesmo dia, matéria sobre o assunto. O Jornal de Londrina diz que "HU volta a enfrentar superlotação no PS", mas observa na abertura, que “o fechamento dos pronto-socorros é rotina no hospital”. Acertou na rotina. Errou no fechamento. A fotografia, pequena e em $\mathrm{P} \& \mathrm{~B}$, traz a legenda "Macas nos corredores são cenário comum no HU”. A imagem (figura 13) mostra uma paciente sentada em uma maca, no corredor, de costas para o fotógrafo. Outro paciente, mais ao fundo, está sendo atendido por um funcionário, aluno ou médico, igualmente de costas. 


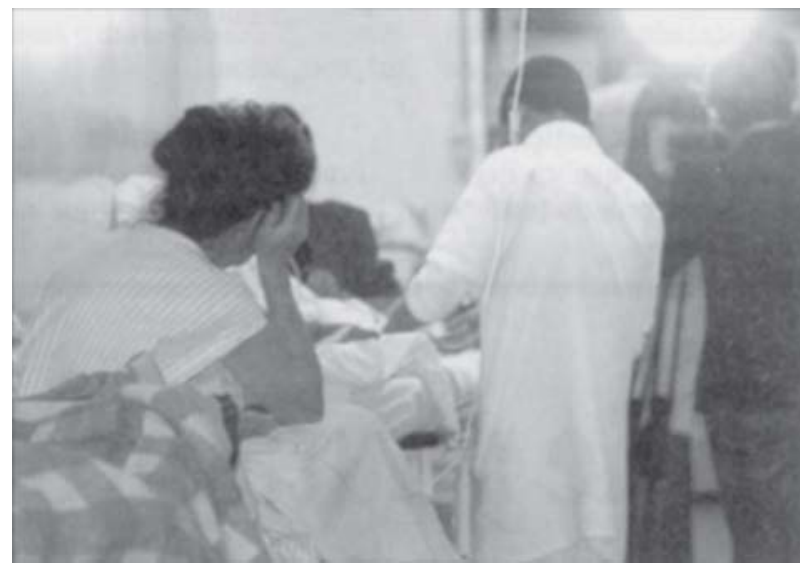

Figura 13 - Jornal de Londrina - 05/11/2004

Foto: Arquivo JL

A Folha de Londrina traz uma fotografia colorida, que ocupa um quarto do espaço da reportagem (figura 14). Está no quadrante superior direito e mostra a enfermaria do Pronto Socorro de Espera. Novamente, não há leitos extras. Pacientes conversam uns com os outros, à direita. À esquerda, um paciente sentado no leito conversa com visitantes. Vale observar que a matéria, a legenda e o crédito referem que o momento retratado é de dois dias antes, mas que na véspera houve suspensão do atendimento.

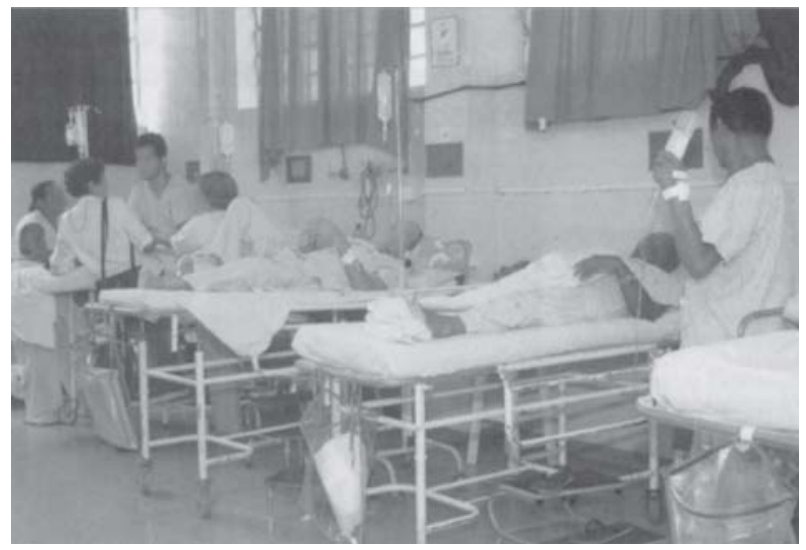

Figura 14 - Folha de Londrina - 05/11/2004

Foto: Karina Yamada 


\section{Considerações finais}

A fotografia valoriza a matéria, não há controvérsia sobre este ponto. Especialmente porque seu conteúdo é trabalhado com competência no que se refere ao trabalho fotojornalístico no momento do registro em si: o uso eventual de cores, o enquadramento, o retrato do humano, os elementos presentes nas fotos, tudo aponta para a perícia técnica do repórter fotográfico. Contudo, numa análise do discurso, o autor não conta. O olhar recai sobre o texto - imagético, no caso.

A observação do corpus, assim, mostra como é pobre a variação das fotografias, mesmo no decorrer de anos. A notícia é a mesma, poderiam dizer os editores. Porém, isso não justifica a falta de criatividade. Em segundo lugar, esta afirmação vem ao encontro do argumento de que a superlotação é rotineira, o que aumenta a dúvida: por que às vezes ela é notícia, e às vezes não? Que assunto precede a este na pauta do dia, e está ausente quando existe o interesse pelo “caos” na saúde pública? Em 2004, apenas uma vez a cada 73 dias, em média, os dois jornais da cidade "concordaram” em tratar o assunto no mesmo dia: duas vezes em janeiro, depois em maio, setembro e novembro.

As macas continuam ocupadas. Aliás, neste exato momento em que o leitor põe os olhos sobre este texto, estão lá os pacientes sendo atendidos sobre elas. Consegue visualizar? Fácil, não? 


\section{Referências}

ARAÚJO, Fernando. HU enfrenta nova superlotação e fecha PS. Jornal de Londrina, Londrina, 29 jan. 2004.

AUGUSTO, Luciano. Pronto-socorro: não há vagas. Folha de Londrina, Londrina, 13 maio 2004.

AVANSINI, Carolina. Crise no HU compromete outros hospitais. Folha de Londrina, Londrina, 5 nov. 2004.

COMELLI, Loriane. Frio e greve da UEL superlotam hospitais. Jornal de Londrina, Londrina, 13 maio 2004.

LOTADO, HU só atende as emergências. Folha de Londrina, Londrina, 11 ago. 1993.

MENEGHEL, Stella. Lotado, pronto-socorro do HU volta a restringir atendimento. Jornal de Londrina, Londrina, 19 jan. 2004.

. HU volta a enfrentar superlotação no PS. Jornal de

Londrina, Londrina, 5 nov. 2004.

NAVARRO, Vanessa. Drama no HU: 60 doentes para 26 vagas.

Folha de Londrina, Londrina, 19 jan. 2004.

ROCHA, Guto. Superlotação suspende atendimento no HU.

Folha de Londrina. Londrina, 29 jan. 2004.

SARIS, Simoni. Cidade enfrenta falta de UTI. Jornal de Londrina, Londrina, 24 set. 2004.

SAVICKI, Adriana. Cinco pacientes aguardam vagas na UTI. Folha de Londrina, Londrina, 24 set. 2004. 